\title{
An investigation on the effect of cognitive emotion regulation strategies on job satisfaction
}

\author{
Somayeh Shahba ${ }^{\mathrm{a}^{*}}$, Seyed Mehdi Alvani ${ }^{\mathrm{a}}$, Shams Alsadat Zahedi ${ }^{\mathrm{b}}$ and Gholamreza Memarzadeh ${ }^{\mathrm{a}}$
}

${ }^{a}$ Department of Management and Accounting, Qazvin Branch, Islamic Azad University, Qazvin, Iran ${ }^{b}$ Department of Management and Accounting, Allameh Tabatabaei University,Tehran, Iran

\section{H R O N I C L E A B T T R C T}

\section{Article history:}

Received December 28, 2013

Received in revised format April

152014

Accepted April 182014

Available online

April 212014

Keywords:

Adjusted strategy

Unadjusted strategy

Cognitive emotion regulation

Job satisfaction

\begin{abstract}
This paper examined the effects of cognitive emotion regulation on employees' job satisfaction. In this survey, Questionnaire and the questions were divided into two categories of cognitive emotion regulation and job satisfaction. To measure cognitive emotion regulation, including unadjusted emotion regulation strategies and adjusted strategies, 36 items questionnaire was used originally developed by Garnefski et al. (2001) [Garnefski, N., Kraaij, V., \& Spinhoven, P. (2001). Negative life events, cognitive emotion regulation, and emotional problems. Personality and Individual Differences, 30, 1311-1327.]. The questionnaires were distributed among 340 staff employee of the Islamic Republic of Iran Customs Administration. The results revealed that the adjusted cognitive emotion regulation strategies increase job satisfaction of employees. However, unadjusted cognitive emotion regulation strategies reduce employees' job satisfaction. Moreover, among adjusted emotion regulation strategies, put in perspective strategy did not have significant effect on job satisfaction and rumination, had no significant effect on job satisfaction, which was one of the unadjusted strategies of cognitive emotion regulation.
\end{abstract}

\section{Introduction}

Emotion is described as one of the most important characteristics of human experience that color and enrich people's lives (Ortony et al., 1988). Emotion and emotion regulation are considered as controversial issue in the field of organization studies (Rafaeli \& Suttorn, 1989). In most organizations, people constantly regulate their emotions and emotion regulations influence either positively or negatively on individuals in the organizations and organizational outcomes (Grendy, 2000). Because of fast technological changes, the increasing environmental complexities, workplace diversity, and the dependence of many service and knowledge-driven organizations to their professionals, the nature of jobs required has been transformed, and many jobs require high mental activities (Russell, 2008). Therefore, for most organizations, subjective well-being and the factors

*Corresponding author.

E-mail addresses: so.shahba@gmail.com (S. Shahba) 
impacting them are very important. Job satisfaction is one of the most important variables for assessment of work-related subjective well-being (Bakker \& Oerlemans, 2010).

In recent years, significant progress in understanding the structure and the role of emotions in human behavior has happened. Community, relationships with friends, colleagues and family are strongly influenced by ability to understand, to interpret and to react to the emotions. In additions, emotions directly and positively influence the intelligence functions such as decision making, perception and the ability to understanding (Isen, 2000; Bechara, 2000). Even beliefs and attitudes, which also Davidson $(1980,1963)$ considered them as the primary reasons are influenced by emotions, and ultimately, emotions dramatically are effective on create action, implementation of action, and monitor and interpret the action (Zhu \&Tnagard, 2002).

There are literally various studies to understand the behavior in the workplace, organizational industrial psychologists, managers and management researchers (Ashforth \& Kreiner, 2002; Levine, 2010; Ashkanasy et al., 2000; Lewis et al., 2010) in the field of emotions in the workplace. However, few studies in the field of emotion regulation, particularly cognitive emotion regulation in organization have been made. Gross (2002) and Kafetsios et al. (2013) recommended that emotion regulation in daily life of all humans is very common, and it is critical and important skill in dealing with personal and social problems. Goldman $(1995,2006)$ and Mayer and salovey (1995) considered it as one of the main variables in emotional intelligence. In addition, emotion regulation has significant impact on well-beings of human (Cicchett et al., 1995; Nyklíček et al., 2011). Thus, it can be expressed that the organization environment is not a rational environment regardless human emotions and the role of emotion regulation in the organizational behavior and human resource management cannot be disregarded.

Most studies in the field of emotion regulation in organization have considered emotional labor, which means the occurrence of emotions according to the organization rules, and the focus of most studies has been on customer service (Hochschild, 1983: Ashforth \& Homphrey, 1993; Abraham, 1998; Grendy, 2000; Cheung \& Tang, 2009; Richards \& Hackett, 2012). While, each organization has different relationships with various people at different stages, the employee will regulate their emotions at any moment of their life, especially when a negative or positive event happens. However, they are concerned on whether all the strategies have the same impact on job satisfaction or the impact of different strategies is different. So far, few studies have examined the effects of cognitive emotion regulation on job satisfaction of employees. Therefore, the need for practical knowledge led to investigate this matter by researchers of this study. Hence, after investigation Theoretical and background research review, the effects of cognitive emotion strategies in two categories: Adjusted and unadjusted setting is investigated.

For the first time Hochschild ( 1983) presented the term of " emotional labor", which means "the management of feeling to create a publicly observable facial and bodily display; emotional labor is sold for a wage and therefore has exchange value". This concept means that business organizations expect their employees to regulate their emotions for business purposes. This process has economic value such as employee's wage and bonus and customer satisfaction and improving performance for organization.

In recent years, due to changes in organizations, especially the development of service industries, several studies have been conducted in the field of emotion regulation, which investigates how emotional expression of employees plays essential role on customers' perception on service quality. Since employees who have relationship with customers are, in fact, interface between the customers and the organization, they introduce organization to their clients (Bowen et al., 1989). In addition, the nature of this service includes intangibility, being variable and heterogeneity and a gap between service providers and customers create the relationship between employees and customers, and also 
interaction between employees, an essential component of determining customer perception towards quality of Service (Bowen et al., 1989; Chi \& Liang, 2013).

According to Thompson (1994) "Emotion regulation consist of the extrinsic and intrinsic processes responsible for monitoring, evaluating and modifying emotional reactions especially their intensive and temporal Features , to accomplish one goals." Cognitive emotion regulation is associated with management and control of emotions during or after a stressful and threatening or positive event occurs (Garnefski, 2001). Cognitions are influenced by emotions (Thagard \& Kroon, 2008) and also influences on emotions (Gross, 2007).

Emotions that humans experience will be influenced by a cognitive process, and it is a subjective process, and emotional assessment is a mental process, which includes analysis of losses and gains of a situation, where a person has been (Zhu \& Thagard, 2002). According to Garnefski et al. (2001), people after the experience of threatening or stressful event use nine categories of cognitive strategies to regulate their emotions. Five strategies are used to adjusted emotion regulation including acceptance, positive reappraisal, planning, putting in perspective and positive refocusing. In addition, they use four strategies as unadjusted emotion regulation, namely self-blame, rumination, catastrophizing, other-blame. These strategies focus on the problem solving with facing the incident and in the present study, these strategies are examined. Overall, these strategies can be defined as follows (Garnefski et al., 2001; 2005):

\section{Unadjusted strategies}

$>$ Self- blame :It means a person blames himself about the event has occurred.

$>$ Other- blame: It means blame others or consider them guilty because of what has happened

$>$ Rumination: Means thinking about the feelings and thoughts of an unpleasant event constantly.

$>$ Catastrophizing: Catastrophizing refers to thinking about uncomfortable issues associated with exacerbating and exaggerating its negative aspects.

Use these strategies reduce well-being and increase anxiety and depression in people.

\section{Adjusted strategies}

$>$ Acceptance: It is pointing to accept responsibility for an event that has happened.

$>$ Refocusing on a plan: Refocusing on the plan refer to think about a negative event and its aspect in order to solve the problem.

$>$ Positive focus: Positive focuses pointing to think about enjoyable parts of a event which has occurred. Positive focus, also called mental disengagement.

$>$ Positive refocusing:It refers to thinking about the positive meanings which can be considered for an event, that means that positive re-evaluation of the event and giving new meaning to it.

$>$ Putting in perspective:This concept refers to thoughts about comparison occurred event with other events, and considering issue less important than other events.

Job satisfaction is the general attitude that a person feels about his/her career. Someone who has a high level of job satisfaction towards his/her job has a positive attitude. Someone who is not satisfied with their job has negative attitudes toward his/her job (Schlett \& Ziegler, 2014). When we talk about attitudes of staff, it often means job satisfaction. Indeed, in this context, usually two issues "job satisfaction" and "attitude" are used, interchangeably. Job satisfaction is influenced by work, the bonus system based on justice, relationship with colleagues and managers (Robbins, 2001). Job satisfaction has been defined by scholars in different ways. Hoppock (1935) defines job satisfaction as any combination of psychological, and physical and environmental conditions that makes the 
person honestly saying he/she is satisfied with his/her job. According to this definition, job satisfaction is influenced by many external factors which cause an inner feeling (Aziri, 2011).

One of the most important defining about job satisfaction is Spector's definition (1997). According to his definition, talking about job satisfaction is the same as talking about feeling of individuals about jobs and its different aspects, and this means that people do what they like about their jobs. Generally, there are two approaches associated with the definition of job satisfaction among researchers and human resources including affective approach and cognitive approach. A group of researchers consider job satisfaction as positive feelings employee about his/her jobs (Spector, 1997; Aziri, 2011; Thompson \& Phua, 2012), and others, pay attention to the cognitive aspect person of his/her job, and they believe that job satisfaction job is a reasonable assessment that a person has about his job, salary, workplace, co-workers and boss (Faullant et al., 2011).

Few studies have been conducted in the field of investigation the relationship between cognitive emotion regulation and job satisfaction, while most studies have been conducted about examining the relationship between job satisfaction and emotional labor (Pugliesi, 1999; Abraham, 1998; Grendy, 2000; Lewig \& Dollard, 2003). Bracket et al. (2010) concluded that there was a positive relationship between emotion regulation and job satisfaction. Cote and Morgan (2002) suggested that amplification of pleasant emotions increases job satisfaction and suppression of unpleasant emotions decreases job satisfaction.

\section{The conceptual research model and hypotheses}

In this section, based on investigation of theoretical and applicable studies described earlier, the conceptual model (Fig. 1) and research hypotheses are presented:

Hypothesis $1\left(\mathrm{H}_{1}\right)$ :

With the increasing use of adjusted emotion regulation strategies by employees, job satisfaction will be increased

Hypothesis 1-1 $\left(H_{1-1}\right)$ : The acceptance strategy influences positively on job satisfaction.

Hypothesis 2-1 ( $\left.\mathrm{H}_{1-2}\right)$ : The positive reappraisal strategy influences on employees' job satisfaction, positively.

Hypothesis 3-1 (H1-3): The planning strategy influences on job satisfaction, positively .

Hypothesis 4-1 (H1-4): The put in perspective strategy has positive effect on employees 'job satisfaction.

Hypothesis 5-1 (H1-5): The positive focus strategy influences on job satisfaction positively.

Hypothesis 2 (H2):

With the increasing of unadjusted emotion regulation strategies by employees, job satisfaction will be decreased.

Hypothesis 1-2 (H2-1): The Self- blame strategy affects son job satisfaction negatively

Hypothesis 2-2 (H2-2): The other- blame strategy influences negatively on employees' job satisfaction.

Hypothesis 3-2 (H2-3): The catastrophizing strategy influences on job satisfaction negatively

Hypothesis 4-2 (H2-4): The rumination strategy influences on job satisfaction negatively. 


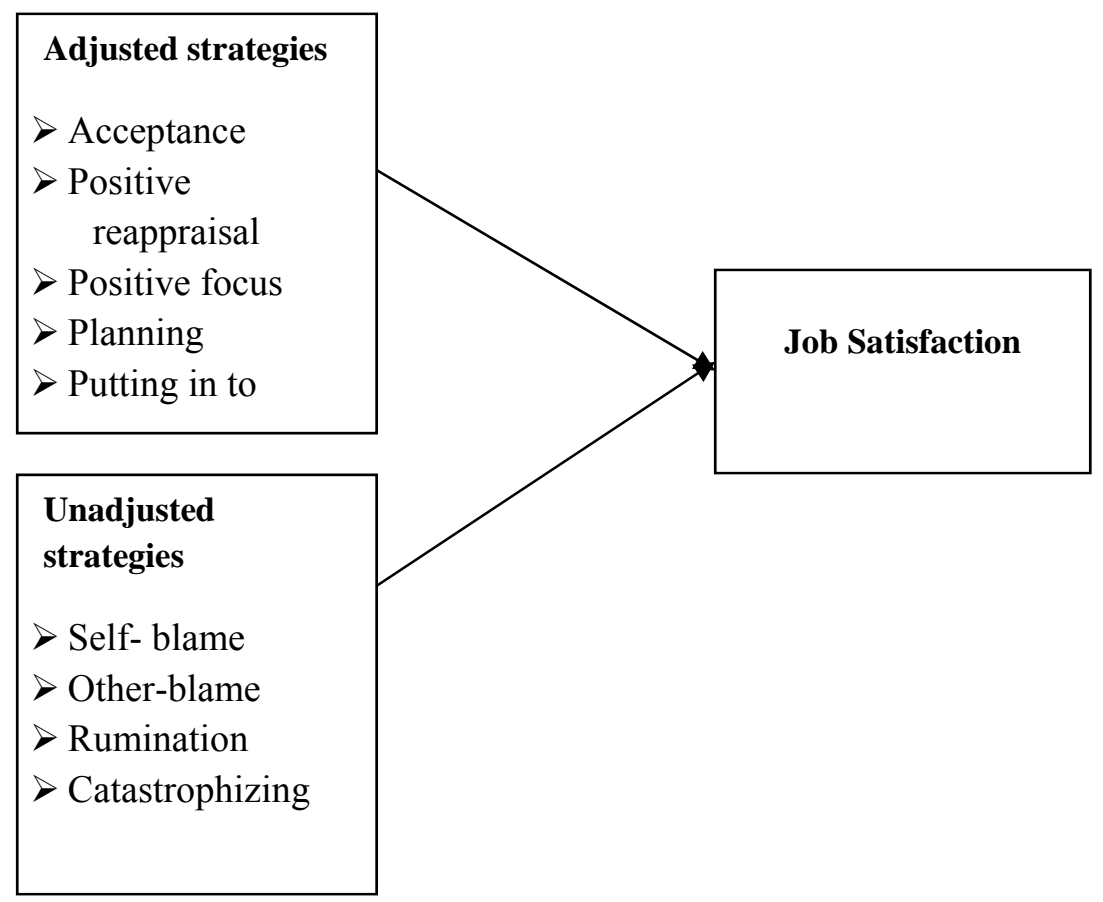

Fig. 1. The conceptual research model

\section{Research Method}

Present study in terms of method is survey -research and in terms of purpose is applied research. The case study is headquarters of the Islamic Republic of Iran Customs Administration. The proposed study of this paper designs a questionnaire and distributed among 450 employees. In order to appreciate those who had completed the questionnaire, gifts were given to employees and we have managed to collect 220 questionnaires, which were valid. Descriptive results indicate that $54.9 \%$ of the participants were women and only $45.1 \%$ of them were men. In terms of age, the highest percentage of participation $(27.7 \%)$ was associated with people aged 36-40 years old. In terms of education, $80 \%$ had a bachelor's degree or higher, which indicates a high level of education of respondents and $85 \%$ of the participants were married. In terms of experience, the highest level of participation was associated with people who had experience between 16-20 years. The lowest percentage was associated with people who had less than 5 years of job experience. In this research, the tool for data collection was Questionnaire and the questions were divided into two categories of Cognitive emotion regulation and job satisfaction. To measure cognitive emotion regulation, including unadjusted emotion regulation strategies and adjusted strategies, 36 items questionnaire according to the Garnefski et al. (2001) was used. Cronbach's alpha was used for measuring reliability of the questionnaire and it was equal to $0.84 \%$. In a study conducted in Iran, the Cronbach's alpha of this questionnaire has been variable between 0.64 to $0.82 \%$ (Abdi et al., 2012). In addition, in this study, to measure job satisfaction, Taylor and Bowers (1974) job satisfaction questionnaire, which measures the degree of employee satisfaction of their relationship with their colleagues and boss, salary, promotion opportunities, and general feedback about his job was used. Generally, in similar studies the reliability of the questionnaire measured using Cronbach's alpha, has been between $0.67 \%$ to $0.71 \%$ (Fields, 2002).

\section{Results}

In this section, we have tried to also explain statistical analysis of the results of applying the path analysis approach, structural equation model in addition to study general features of the subjects. Structural Equations Modeling (SEM) is a statistical technique for simultaneously examining and estimating causal relationships among multiple independent and dependent constructs. Confirmatory factor analysis (CFA) using Smart PLS has been used for 210 respondents. Partial Least Square 
(PLS) technique has been used to validate the measurements and to test hypotheses using SmartPLS 2.0 software. The PLS technique employs a component-based approach for model estimation and is best suited for testing complex structural models. The PLS technique was selected since it does not impose any normality requirements on the data. A two-step approach has been used to first assess the quality of measures (as per this research study) using the measurement model (outer model), and then to test the hypotheses using the structural model (inner model).

\subsection{Results of confirmatory factor analysis and measurement models}

Table demonstrates the results of factor analysis and measurement of the models.

\section{Table 1}

Validity, Composite reliability and factor loadings

\begin{tabular}{|c|c|c|c|c|c|}
\hline & latent variables & Items & Factor loading & AVE & $\mathrm{CR}$ \\
\hline \multirow{18}{*}{$\begin{array}{l}\text { First order } \\
\text { confirmatory } \\
\text { factor analysis }\end{array}$} & \multirow{3}{*}{ Reception } & acc1 & 0.588 & \multirow{3}{*}{0.569} & \multirow{3}{*}{0.794} \\
\hline & & acc2 & 0.771 & & \\
\hline & & acc3 & 0.875 & & \\
\hline & \multirow{4}{*}{ Positive evaluation } & Preap1 & 0.755 & \multirow{4}{*}{0.603} & \multirow{4}{*}{0.858} \\
\hline & & Preap2 & 0.752 & & \\
\hline & & Preap3 & 0.769 & & \\
\hline & & Preap4 & 0.827 & & \\
\hline & \multirow{3}{*}{ Planning } & Plan1 & 0.808 & \multirow{3}{*}{0.688} & \multirow{3}{*}{0.869} \\
\hline & & Plan2 & 0.858 & & \\
\hline & & Plan3 & 0.821 & & \\
\hline & \multirow{4}{*}{ Put in perspective } & PtP1 & 0.543 & \multirow{4}{*}{0.503} & \multirow{4}{*}{0.726} \\
\hline & & PtP2 & 0.666 & & \\
\hline & & PtP3 & 0.757 & & \\
\hline & & PtP4 & 0.548 & & \\
\hline & \multirow{4}{*}{ Positive Focus } & Pref1 & 0.824 & \multirow{4}{*}{0.560} & \multirow{4}{*}{0.833} \\
\hline & & Pref2 & 0.826 & & \\
\hline & & Pref3 & 0.689 & & \\
\hline & & Pref4 & 0.611 & & \\
\hline \multirow{5}{*}{$\begin{array}{l}\text { Second order } \\
\text { confirmatory } \\
\text { factor analysis }\end{array}$} & \multirow{5}{*}{ Adjusted strategies } & Reception & 0.454 & \multirow{5}{*}{0.503} & \multirow{5}{*}{0.833} \\
\hline & & Positive evaluation & 0.865 & & \\
\hline & & Planning & 0.747 & & \\
\hline & & Putting in perspective & 0.802 & & \\
\hline & & Positive Focus & 0.598 & & \\
\hline \multirow{13}{*}{$\begin{array}{l}\text { First order } \\
\text { confirmatory } \\
\text { factor analysis }\end{array}$} & & $\mathrm{Sb} 1$ & 0.675 & & \\
\hline & Self-blame & $\mathrm{Sb} 2$ & 0.563 & 0.519 & 0.759 \\
\hline & & $\mathrm{Sb} 3$ & 0.882 & & \\
\hline & & $\mathrm{BO} 1$ & 0.628 & & \\
\hline & Other-blame & $\mathrm{BO} 2$ & 0.796 & 0600 & $0856>>2>$ \\
\hline & Other- blame & $\mathrm{BO} 3$ & 0.860 & 0.600 & 0.856 \\
\hline & & $\mathrm{BO} 4$ & 0.797 & & \\
\hline & & Cat1 & 0.885 & & \\
\hline & Catastrophizing & Cat2 & 0.851 & 0.675 & 0.861 \\
\hline & & Cat3 & 0.719 & & \\
\hline & & Rum1 & 0.770 & & \\
\hline & Rumination & Rum2 & 0.649 & 0.556 & 0.788 \\
\hline & & Rum3 & 0.808 & & \\
\hline & & Self-blame & 0.491 & & \\
\hline & Unadiusted strategies & Other-blame & 0.668 & 0550 & 0762 \\
\hline & Unadjusted strategies & Catastrophizing & 0.821 & 0.550 & 0.762 \\
\hline & & Rumination & 0.662 & & \\
\hline & & JS1 & 0.602 & & \\
\hline & & JS10 & 0.632 & & \\
\hline First order & & JS2 & 0.643 & & \\
\hline factor analysis & & JS3 & 0.616 & & \\
\hline & Joh satisfaction & JS4 & -0.537 & 0538 & $0838>2>-1$ \\
\hline & Job satistaction & JS5 & 0.678 & & 0.838 \\
\hline & & JS6 & 0.601 & & \\
\hline & & JS7 & 0.779 & & \\
\hline & & JS8 & 0.817 & & \\
\hline & & JS9 & 0.568 & & \\
\hline
\end{tabular}


As we can observe from the results of Table 1, the calculated $t$ value for each of the factor loadings of each indicator or latent variables is bigger than 1.96. Therefore, we can show alignment questionnaire questions to validate concepts revealed at this stage. In fact, these results indicate that what has been achieved by questions intended to measure them by this tool has been realized. Therefore, the relationships between structures or latent variables are invoked. In addition, all factor loadings, some larger than 0.5 are given, which validates the index. To structure validity used to examine the importance of selected indicators to measure structures, discriminant validity is considered in this study meaning that indicators each structure provided appropriate separation in terms of the measurement relative to other structures of model (Table 3). In simple terms, each indicator must measure only its structure, and their combination must be such that all the ingredients are well separated. With the help of the average variance extracted (AVE) determined that all of the studied structures have average variance extracted well above 0.5 . Composite reliability index (CR) to verify the reliability is used and all coefficients were greater than 0.7 , which confirms the overall questionnaire. The index of determination shows what percentage changes of a dependent variable are explained by the independent variable or variables. Accordingly, adjusted and unadjusted strategies variables together can explain $19.8 \%$ of variables changes of the job satisfaction.

Table 2

Discriminant validity

\begin{tabular}{|c|c|c|c|c|c|c|c|c|c|c|c|}
\hline & Latent variable & 1 & 2 & 3 & 4 & 5 & 6 & 7 & 8 & 9 & 10 \\
\hline 1. & Acceptance & 0.763 & & & & & & & & & \\
\hline 2. & Blame others & -0.068 & 0.759 & & & & & & & & \\
\hline 3. & Catastrophizing & 0.1199 & 0.3869 & 0.822 & & & & & & & \\
\hline 4. & Job satisfaction & 0.2132 & -0.2353 & -0.1799 & 0.726 & & & & & & \\
\hline 5. & Planning & 0.2307 & -0.1141 & -0.1111 & 0.2896 & 0.829 & & & & & \\
\hline 6. & Positive reappraisal & 0.2358 & -0.0011 & -0.1563 & 0.3558 & 0.684 & 0.775 & & & & \\
\hline 7. & Positive refocusing & 0.2037 & -0.0356 & -0.0133 & 0.2759 & 0.4299 & 0.4934 & 0.738 & & & \\
\hline 8. & Putting in to perspective & 0.1479 & -0.231 & 0.0362 & 0.2194 & 0.3147 & 0.3868 & 0.4 & 0.709 & & \\
\hline 9. & Rumination & 0.2688 & 0.1767 & 0.3345 & -0.2285 & -0.364 & -0.3648 & -0.2468 & -0.3028 & 0.741 & \\
\hline 10. & Self-blames & 0.3198 & 0.0393 & 0.2119 & -0.2144 & -0.083 & -0.1441 & -0.1096 & -0.1735 & 0.2123 & 0.758 \\
\hline
\end{tabular}

Note: Diagonals represent the square root of the AVE while the off-diagonals represent the correlations

The goodness-of-fit (GOF) measure has been conducted for assessment of this research PLS path modeling (Amato et al., 2004). GOF is suggested as a global fit measure for PLS path modeling. GOF $(0<\mathrm{GOF}<1)$ is defined as the geometric mean of the average AVE and average R2 (for endogenous constructs).

$G O F=\sqrt{\overline{A V E}} \times \sqrt{\overline{R^{2}}}$

Following the guidelines of the GOF value has been calculated, which validates the PLS model of this research study. The GOF value for this research model is 0.544 . The GOF value for the model exceeds the minimum cut-off value of 0.198 for large effect sizes of R2. The GOF value provides adequate support to validate the PLS model. The baseline values for validating the PLS model globally are GOF small $=0.1$, GOF medium $=0.25$ and GOF large $=0.36$ (Akter et al., 2011) .

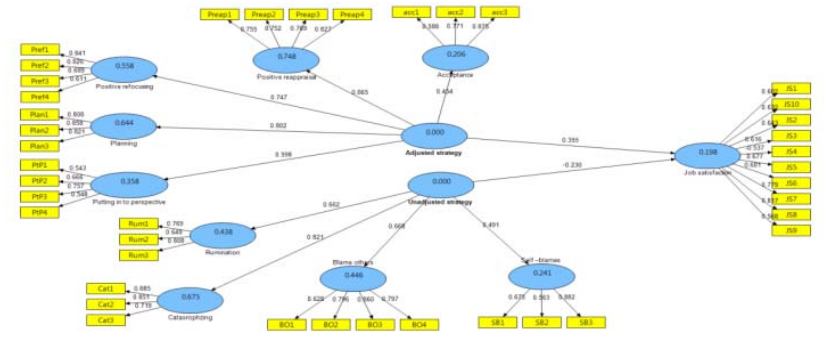

Fig. 2. Results of PLS structural model analysis (Smart PLS export image)

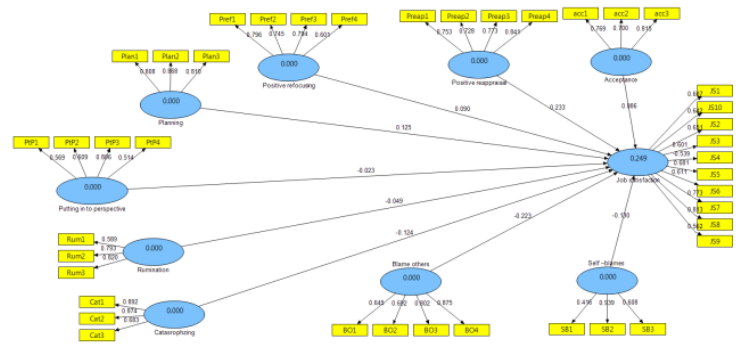

Fig. 3. Results of PLS structural Sub model analysis (Smart PLS export image) 


\subsection{Assessment of the structural model the results of the hypotheses test}

In this part of the research, in order to test effect and causal relationships set among strategies of emotions regulation (adjusted and unadjusted) on job satisfaction, structural equation model was used. Next, the hypotheses generated out of this research were tested by examining the structural model using Smart PLS2 software. The structural model includes estimating the path coefficients, which indicates the strength of the relationships between the independent variables and dependent variable and $\mathrm{R}$-square value (variance explained by the independent variables). A bootstrapping resampling procedure (Davison \& Hinkley, 1997) of 220 samples was used to determine the significance level of the paths defined within the structural model (Amatos, 2004). Bootstrapping results in a larger sample claimed to model the unknown population. The corresponding t-values show the level of significance using the magnitude of the standardized parameter estimates between the constructs. 10\% significance level $(\mathrm{p}<0.1) 5 \%$ significance level $(\mathrm{p}<0.05)$ and $1 \%$ significance level $(\mathrm{p}<0.01)$ is used as a statistical decision criterion. The results of the structural model are summarized in Table 3. Out of the eleven hypotheses, nine are supported. The variance explained ranges from 0.198 to 0.249 . From the analysis it was found Adjusted strategy $(\beta=0.332, p<0.01)$ was positively relate to Job Satisfaction. Unadjusted strategy $(\beta=-0.230, p<0.01)$ was negatively associated with Job Satisfaction. The Acceptance $(\beta=0.086, p<0.1)$, Planning $(\beta=0.125, p<0.1)$ and Positive evaluation $(\beta=0.233, p<0.01)$ were positively associated with Job satisfaction, the other- blame $(\beta=-0.223, p<0.01)$, Catastrophizing $(\beta=-0.124, p<0.01)$ and Self- blame $(\beta=-0.13$, $\mathrm{p}<0.01)$ were negatively relate to Job satisfaction. The of Put in perspective $(\beta=-0.023, p>0.1)$ and Rumination $(\beta=-0.049, p<0.1)$ are not relate to Job satisfaction

\section{Table 3}

Path coefficients, t-statistics and the results of research hypotheses

\begin{tabular}{clllll}
\hline Research hypotheses & & Impact Factor & Statistics & Sig & Result \\
\hline \multirow{2}{*}{ Main } & Adjusted Strategies $>$ Job Satisfaction & 0.355 & 8.332 & $\mathrm{P}<0.01$ & Confirmed \\
& Unadjusted Strategies - $>$ Job Satisfaction & -0.230 & -4.350 & $\mathrm{P}<0.01$ & Confirmed \\
\hline \multirow{5}{*}{ Subsidiary } & Acceptance- $>$ Job Satisfaction & 0.086 & 1.833 & $\mathrm{P}<0.1$ & Confirmed \\
& Other- blame - $>$ Job Satisfaction & -0.223 & -4.630 & $\mathrm{P}<0.01$ & Confirmed \\
& Catastrophizing- $>$ Job Satisfaction & -0.124 & -2.255 & $\mathrm{P}<0.05$ & Confirmed \\
& Planning - $>$ Job Satisfaction & 0.125 & 1.947 & $\mathrm{P}<0.1$ & Confirmed \\
& Positive evaluation- $>$ Job Satisfaction & 0.233 & 3.678 & $\mathrm{P}<0.01$ & Confirmed \\
& Positive focus - $>$ Job Satisfaction & 0.090 & 1.865 & $\mathrm{P}<0.1$ & Confirmed \\
& Put in perspective - $>$ Job Satisfaction & -0.023 & 0.400 & $\mathrm{P}>0.05$ & Rejected \\
& Rumination- $>$ Job Satisfaction & -0.049 & 0.871 & $\mathrm{P}>0.05$ & Rejected \\
& Self- blame - $>$ Job Satisfaction & -0.13 & 2.403 & $\mathrm{P}<0.05$ & Confirmed \\
\hline
\end{tabular}

\section{Discussion and conclusions}

In this study, we have investigated the effect of emotion regulation strategies, adjusted and unadjusted, on job satisfaction. Based on the results of the first hypothesis, adjusted strategies were significantly associated with job satisfaction. However, among adjusted strategies, put in perspective strategy have had no effect on job satisfaction. The second hypothesis was also confirmed in this study, which suggests that unadjusted emotion regulation strategies in addition to increasing depression and anxiety (Garnefski et al., 2001), they reduce job satisfaction of employees in the organization, so people who use unadjusted emotion regulation strategies in case of negative events, also reported lower job satisfaction. Moreover, among unadjusted emotion regulation strategies, rumination strategy has had no effect on job satisfaction. So far a lot of studies have been conducted on job satisfaction, and many factors including organizational conditions such as payment, promotion opportunities and working conditions and group relation, including relationship with colleagues and supervisors as well as personal differences, including motivation, needs and personality are considered as factors affecting job satisfaction (Spector, 1997; Griffin \& Moorhead, 2011). But so far, few studies have examined the effect of adjusted and unadjusted cognitive emotion regulation strategies on job satisfaction. This study is a progress in the field of organizational behavior and 
human resource management studies in order to present another factor that influencing on job satisfaction. Sometimes some employees are not satisfied with their lives or their works, not only as a result of organizational condition or group factor but also because of how they think and how they regulate their emotions when negative or positive events happens.

\section{References}

Abdi, S., Taban, S., \& Ghaemian, A. (2012). Cognitive emotion regulation questionnaire: Validity and reliability of Persian translation of CERQ-36 item. Procedia-Social and Behavioral Sciences, 32, 2-7.

Abraham, R. (1998). Emotional dissonance in organizations: antecedents, consequences, and moderators. Genetic, Social and General Psychology Monographs, 124, 229-246.

Akter, S., D'Ambra, J., \& Ray, P. (2011). An evaluation of PLS based complex models: the roles of power analysis, predictive relevance and GoF index. Proceedings of the 17th Americas Conference on Information Systems (AMCIS2011) (pp. 1-7). Detroit, USA: Association for Information Systems.

Amato, S., Esposito Vinzi, V., \& Tenenhaus, M. (2004). A global goodness-of-fit index for PLS structural equation modeling. Oral Communication to PLS Club, HEC School of Management, France, March, 24.

Ashforth, B. E., \& Humphrey, R. H. (1993). Emotional labor in service roles: the influence of identity. Academy of Management Review, 18, 88-115.

Ashforth, B.E., \& Kreiner, G.E. (2002), Normalizing emotion organization: Making the extraordinary seem ordinary. Human Resource management review, 12(2), 215-235

Ashkanasy, N. M., Hartel, C.E.J., \& Zerbe, W. J. (Eds.). (2000). Emotions in the workplace: Research, theory, and practice. Westport, CT: QuorumBooks.

Aziri, B. (2011). Job satisfaction: a literature Review. Management Research \& Practice, 3(4), 77-86

Bakker, A.B., \& Oerlemans, W.G.M. (2010). Subjective well-being in organizations,(Eds), Handbook of Positive Organizational Scholarship. Oxford University Press

Bechara, A., Damasio, H., \& Damasio, A. R. (2000). Emotion, decision making and the orbitofrontal cortex. Cerebral Cortex, 10(3), 295-307.

Bowen, D. E., Siehl, C., \& Schneider, B. (1989). A framework for analyzing customerservice orientations in manufacturing. Academy of Management Review, 14, 75-95

Bracket, M. R., Palomera, R., Mojsa-Kaja, J., Reyes, \& M. R., \& Salovey, P. ( 2010). Emotionregulation ability, burnout and Job satisfaction among British secondary - school teachers, psychology in the school, 47, 406-417.

Cheung, F. Y. L., \& Tang, C. S. K. (2009). Quality of work life as a mediator between emotional labor and work family interference. Journal of Business and Psychology, 24(3), 245-255.

Chi, S. S., \& Liang, S. G. (2013). When do subordinates' emotion-regulation strategies matter? Abusive supervision, subordinates' emotional exhaustion, and work withdrawal, The Leadership Quarterly, 24(1), 125-137.

Cicchett, D., Ackerman, B. P., \& Izard, C. E. (1995), emotion and emotion regulation in developmental psychopathology. Development and psychopathology, 7, 1-10.

Cote, S., \& Morgane, M.L. (2002). A longitudinal analysis of the association between emotion regulation, job satisfaction, and intentions to quit. Journal of Organizational Behavior, 23, 947-962.

Davison, A. C., \& Hinkley, D. V. (1999). Bootstrap Methods and Their Applications.

Faullant, R., Matzler, K., \& Mooradian, T. A. (2011), Personality, basic emotions, and satisfaction: Primary emotions in the mountaineering experience. Tourism Management, 32(6),1423-1430.

Fields, D. L. (2002). Taking the measure of work: A guide to validated scales for organizational research and diagnosis. Regent University: Sage.

Garnefski, N., Baan, N., \& Kraaij, V. (2005). Psychological distress and cognitive emotion regulation strategies among farmers who feel victim to the foot-and-mouth crisis. Personality and Individual Differences, 38, 1317-1327.

Garnefski, N., Kraaij, V., \& Spinhoven, P. (2001). Negative life events, cognitive emotion regulation, and emotional problems. Personality and Individual Differences, 30, 1311-1327. 
Goldman, D. (1995). Emotional intelligence. New York: Bantam Books.

Goldman, D. (2006). Emotional intelligence. Random House LLC.

Grendy, A.A. (2000). Emotion regulation in the workplace: a new way to conceptualize emotional labor, Journal of Occupational Health Psychology, 5(1), 95-110.

Griffin, R., \& Moorhead, G. (2011). Organizational behavior. Cengage Learning.

Gross, J.J. (2002). Emotion regulation: Affective, cognitive, and social consequences. Psychophysiology, 39, 281-291.

Gross, J. J., \& Thompson, R. A. (2007). Emotion regulation: Conceptual foundations. In J. J. Gross (Ed.), Handbook of emotion regulation New York: Guilford Press.

Hochschild, A. R. (1983). The managed heart. Berkeley: University of California Press. Homewood, IL: Dow Jones-Irwin.

Hoppock, R. (1935). Job Satisfaction, Harper and Brothers, New York.

Isen, A. M. (2000). Positive Affect and Decision Making. In Handbook of emotions (pp. 417-435). New York: Guilford Press.

Kafetsios, K., Athanasiadou, M., \& Dimou, N. (2013). Leaders' and subordinates' attachment orientations, emotion regulation capabilities and affect at work: A multilevel analysis. The Leadership Quarterly, 20(4), 119-131.

Levine, E. L. (2010). Emotion and power (as social influence): Their impact on organizational citizenship and counterproductive individual and organizational behavior. Human resource management Review, 20(1), 4-17.

Lewig, K. A., \& Dollard, M. F. (2003). Emotional dissonance, emotional exhaustion and job satisfaction in call centre workers. European Journal of Work and Organizational Psychology, 12, 366-392.

Lewis, M., Haviland-Jones, J. M., \& Barrett, L. F. (2010). Handbook of emotions. Guilford Press

Mayer, J. D., \& Salovey, P. (1995). Emotional intelligence and the construction and regulation of feelings. Applied and Preventive Psychology, 4(3), 197-208.

Nyklíček, I., Vingerhoets, A. J. J. M., \& Zeelenberg, M. (2011). Emotion Regulation and Well-being. Springer.

Ortony, A., Clore, G., \& Collins, A. (1988). The cognitive structure of emotion, Cambridge, Cambrige university press.

Quoidbach, J., Berry, E.V., Hansenne, M., \& Mikolajczak, M. (2010). Positive emotion regulation and well-being: Comparing the impact of eight savoring and dampening strategies. Personality and Individual Differences, 49, 368-373.

Pugliesi, K. (1999). The consequences of emotional labor: Effects on work stress, job satisfaction, and well-being. Motivation and Emotion, 23, 125-154.

Rafaeli, A., \& Sutton, R. I. (1989). The expression of emotion in organizational life. Research in organizational behavior, 11, 1-42.

Richards, D. A., \& Hackett, R. D. (2012). Attachment and emotion regulation: Compensatory interactions and leader-member exchange. The Leadership Quarterly, 23(4), 686-701.

Robbins, S. P. (2001). Organizational Behavior, 14/e. Pearson Education India.

Russell, J. E. (2008). Promoting subjective well-being at work. Journal of Career Assessment, 16(1), 117-131.

Schlett, C., \& Ziegler, R. (2014). Job emotions and job cognitions as determinants of job satisfaction: The moderating role of individual differences in need for affect. Journal of Vocational Behavior, 84(1), 74-89.

Spector, P. E. (1997). Job satisfaction: Application, assessment, cause, and consequences. Thousand Oaks, CA: Sage.

Thagard, P., \& Kroon, F. (2008). Hot thought: Mechanisms and applications of emotional cognition.

Thompson, R. A. (1994). Emotion regulation: A theme in search of definition. Monographs of the society for research in child development, 59(23), 25-52.

Thompson, E. R., \& Phua, F. T. (2012). A brief index of affective job satisfaction. Group \& Organization Management, 37(3), 275-307.

Zhu. J., \& Thagard. P. (2002). Emotion and action, Philosophical. Psychology, 15, 19-36. 